OPEN ACCESS

Edited by:

Cesare Piazza,

University of Brescia, Italy

Reviewed by: Achille Tarsitano,

University of Bologna, Italy

Constantinus Politis,

University Hospitals Leuven, Belgium

*Correspondence:

Gustaaf J. C. van Baar g.vanbaar@amsterdamumc.nl

Specialty section:

This article was submitted to Head and Neck Cancer,

a section of the journal

Frontiers in Oncology

Received: 16 November 2020 Accepted: 05 January 2021

Published: 22 February 2021

Citation:

van Baar GJC, Leeuwrik L,

Lodders JN, Liberton NPTJ,

Karagozoglu KH, Forouzanfar T and Leusink FKJ (2021) A Novel Treatment

Concept for Advanced Stage

Mandibular Osteoradionecrosis

Combining Isodose Curve

Visualization and Nerve Preservation: A

Prospective Pilot Study.

Front. Oncol. 11:630123.

doi: 10.3389/fonc.2021.630123

\section{A Novel Treatment Concept for Advanced Stage Mandibular Osteoradionecrosis Combining Isodose Curve Visualization and Nerve Preservation: A Prospective Pilot Study}

Gustaaf J. C. van Baar ${ }^{1 *}$, Lars Leeuwrik ${ }^{1}$, Johannes N. Lodders ${ }^{1}$, Niels P. T. J. Liberton ${ }^{2}$, K. Hakki Karagozoglu ${ }^{1}$, Tymour Forouzanfar ${ }^{1}$ and Frank K. J. Leusink ${ }^{1}$

${ }^{1}$ Amsterdam UMC and Academic Centre for Dentistry Amsterdam (ACTA), Vrije Universiteit Amsterdam, Department of Oral and Maxillofacial Surgery/Pathology, Amsterdam, Netherlands, ${ }^{2}$ Amsterdam UMC, Vrije Universiteit Amsterdam, Medical Technology, 3D Innovation Lab, Amsterdam, Netherlands

Background: Osteoradionecrosis (ORN) of the mandible is a severe complication of radiation therapy in head and neck cancer patients. Treatment of advanced stage mandibular osteoradionecrosis may consist of segmental resection and osseous reconstruction, often sacrificing the inferior alveolar nerve (IAN). New computer-assisted surgery (CAS) techniques can be used for guided IAN preservation and 3D radiotherapy isodose curve visualization for patient specific mandibular resection margins. This study introduces a novel treatment concept combining these CAS techniques for treatment of advanced stage ORN.

Methods: Our advanced stage ORN treatment concept includes consecutively: 1) determination of the mandibular resection margins using a 3D 50 Gy isodose curve visualization, 2) segmental mandibular resection with preservation of the IAN with a twostep cutting guide, and 3) 3D planned mandibular reconstruction using a hand-bent patient specific reconstruction plate. Postoperative accuracy of the mandibular reconstruction was evaluated using a guideline. Objective and subjective IAN sensory function was tested for a period of 12 months postoperatively.

Results: Five patients with advanced stage ORN were treated with our ORN treatment concept using the fibula free flap. A total of seven IANs were salvaged in two men and three women. No complications occurred and all reconstructions healed properly. Neither non-union nor recurrence of ORN was observed. Sensory function of all IANs recovered after resection up to 100 percent, including the patients with a pathologic fracture due to ORN. The accuracy evaluation showed angle deviations limited to 3.78 degrees. Two deviations of $6.42^{\circ}$ and $7.47^{\circ}$ were found. After an average of 11,6 months all patients received dental implants to complete oral rehabilitation. 
Conclusions: Our novel ORN treatment concept shows promising results for implementation of $3 \mathrm{D}$ radiotherapy isodose curve visualization and IAN preservation. Sensory function of all IANs recovered after segmental mandibular resection.

Keywords: osteoradionecrosis, mandibular reconstruction, inferior alveolar nerve, treatment, computerassisted surgery

\section{INTRODUCTION}

Osteoradionecrosis (ORN) of the jaws is a common side effect of radiation therapy (RT) (1-4). ORN is defined as the process where irradiated bone becomes necrotic and exposed for a time period of at least 3 months, and fails to heal (5-8). It affects the mandible, in particular the body, more often than the maxilla or any other bone of the head and neck area (9) and has an incidence in the mandible between $2 \%$ and $22 \%(10,11)$. Although ORN is often diagnosed within 2 years after RT, there is a lifelong risk for this severe complication (12).

Risk factors associated with ORN are well documented $(8,13-$ $15)$, with the most prominent being the radiation dose. A radiation dose more than $60 \mathrm{~Gy}$ is reported as high risk and $50-60 \mathrm{~Gy}$ as intermediate risk $(4,8,15-17)$. In the management of ORN prevention is crucial since the process is irreversible and progression is difficult to control. Once ORN is diagnosed conservative measurements are indicated (18-20). For advanced stages of ORN these conservative measurements alone are not sufficient.

There are different ORN classification systems described in the literature, however the Notani classification (21) seems to be the most reliable for determining progression of ORN in the mandible (Table 1) (22). In advanced stage ORN (Notani stage III), segmental mandibular resection may be indicated $(13,18$, 19). However, determining resection margins may be difficult as the extent, severity, and location of ORN do not always correlate with radiographical imaging (23).

Computer-assisted surgery (CAS) is well known in mandibular resection and reconstruction since its introduction by Hirsch in $2009(24,25)$ introducing high accuracy results and shortened operation time (26-30). In addition, CAS can facilitate incorporation of intensity modulated radiation therapy (IMRT) data in the virtual planning of segmental mandibular resection and reconstruction. As radiation dose seems to correlate with the risk for ORN (15), Kraeima et al. (2018) incorporated RT isodose curves in the virtual planning of the resection using a threedimensional image of the administered RT dose of 50 Gy (31). With this patient-specific technique, the mandibular resection

TABLE 1 | The Notani classification for mandibular osteoradionecrosis.

Stage I Osteoradionecrosis confined to the alveolar bone

Stage II Osteoradionecrosis limited to the alveolar bone or the mandible, or both above the mandibular alveolar canal

Stage III Osteoradionecrosis that extended to the mandible under the level of the mandibular alveolar canal and osteoradionecrosis with a skin fistula or a pathological fracture, or both can be planned highly accurate out of the irradiated bone, leading to a minimally invasive mandibular resection.

Although the inferior alveolar nerve (IAN) is not directly affected in ORN cases, the nerve is often sacrificed during mandibular resection. Injury of the IAN may have a significant negative impact on quality of life as it may cause chronic pain (32). Additionally, maintaining sensorimotoric function of the lower lip and chin may be beneficial for oral function such as speech and mastication (33). Free handed preservation of the IAN is time consuming $(34,35)$ and includes a considerable risk of iatrogenic nerve injury (36). The use of CAS techniques for preserving the IAN during segmental mandibular resection has been evaluated by previous studies (37-40), showing promising results to prevent sensory disturbance of the lip and chin region. After segmental resection of necrotic bone, mandibular continuity can be restored with a vascularized bone flap covering the defect with non-irradiated soft-tissue (41). Currently, the fibula free flap (FFF) is the most commonly used reconstruction approach (42-44).

In this prospective pilot study we combined RT isodose curve visualization with 3D guided IAN preservation in order to improve quality of life. Research to date has not yet combined these two CAS techniques. The accuracy of the mandibular reconstructions were evaluated postoperatively (45). In all cases the postoperative IAN sensory function was objectified and compared with the preoperative function. A visual analog scalebased questionnaire was used to evaluate subjective sensibility.

\section{MATERIALS AND METHODS}

\section{Patients}

This study was conducted in the Department of Oral and Maxillofacial Surgery/Oral Pathology, Amsterdam UMC, VU University Medical Center Amsterdam (the Netherlands) and was approved by the Medical Ethics Review Committee of VU University Medical Center (FWA 00017598). Between November 2017 and March 2019 all ORN stage III patients (minimum age of 18 years) who received IMRT in the past with an indication for segmental mandibular resection were included. Patients with diagnosed malignancies were excluded.

\section{Preoperative Imaging}

A preoperative multi-detector row computed tomography (MDCT) scan $(\mathrm{kVp} 120$, mAs 300, slice thickness $0.625 \mathrm{~mm}$ ) was made of the skull using a GE Discovery CT750 HD 64-slice MDCT scanner (GE Healthcare, Little Chalfont, Buckinghamshire, UK). The lower leg 
was scanned with CT angiography (CTA) for visualization of the fibula including vessel anatomy. Both Digital

Imaging and Communications in Medicine (DICOM) files were uploaded in Mimics Medical 21.0 software (Materialise, Leuven, Belgium) and converted into $3 \mathrm{D}$ models using the thresholding tool; voxels with an $\mathrm{HU}$ above a selected threshold value are included in the ROI and transformed into 3D surface models in the Standard Tessellation Language (STL) file format (46).

\section{Isodose Curve Visualization}

In the RT software (Eclipse ${ }^{\mathrm{TM}}$, external beam planning V15.6, Varian medical systems, Palo Alto, CA, USA) the 50 Gy isodose borders from the IMRT data were determined, converted into a $3 \mathrm{D}$ model, and superimposed on the 3D model of the mandible. Subsequently the mandibular resection margins were determined on the mandible, taking into account the above mentioned isodose curve visualization and the optimal direction of the osteotomy planes for FFF reconstruction. Remnant mandibular bone outside the resection was checked for the signs of ORN on CT (mono- or bicortical destruction, central necrosis, and sequestration) (23). Figure 1 shows an example of a 3D model with the bone that had been exposed to a high risk dose of $50 \mathrm{~Gy}$ or more.

\section{IAN Localization}

The mandibular canal was traced using the tool "trace thin structure" in Mimics Medical 21.0 in a coronal view from the mandibular foramen to the mental foramen in steps of $2 \mathrm{~mm}$. Once the canal was marked, the tracing was checked in sagittal view of the CT scan. The same procedure was used for the other side. The traced canals were exported in STL format. The mandible was also segmented and exported in STL format (Figure 2).

\section{Guide Design and Manufacturing}

ProPlan CMF 2.1. software (Materialise, Leuven, Belgium) was used to design the osteotomy planes on the mandible and to determine the optimal position and configuration of the fibula

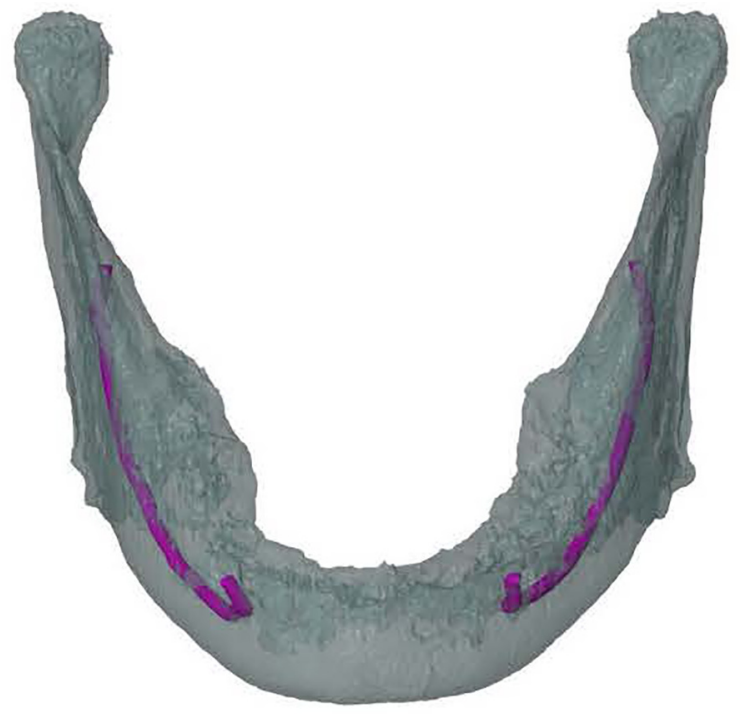

FIGURE 2 | Frontal view of a 3D model of the mandible including inferior alveolar nerve tracing (in purple) on the left and the right.

segments to reconstruct the mandibular defect (25) (Figure 3). This virtual model was $3 \mathrm{D}$ printed and figured as a template to pre-bent a KLS Martin $2.7 \mathrm{~mm}$ reconstruction plate into a patient specific reconstruction plate (PSRP) (Figure 4). Subsequently a CT scan of the PSRP was made, converted to STL format, and used further along in the virtual planning to determine the locations of the fixation screws.

All cutting guides were designed using 3-Matic Medical software 14.0 (Materialise, Leuven, Belgium). To preserve the IAN a two-step mandibular guide was created with a free margin of $2 \mathrm{~mm}$ cranially to allow two-step deroofing of the superior and lateral cortex of the mandibular canal. When using CT data for manual mandibular canal tracing a safety zone of $1.7 \mathrm{~mm}$ should be taken into account (47). A template design with cutting guides is shown in Figure 5. The STL files of the cutting
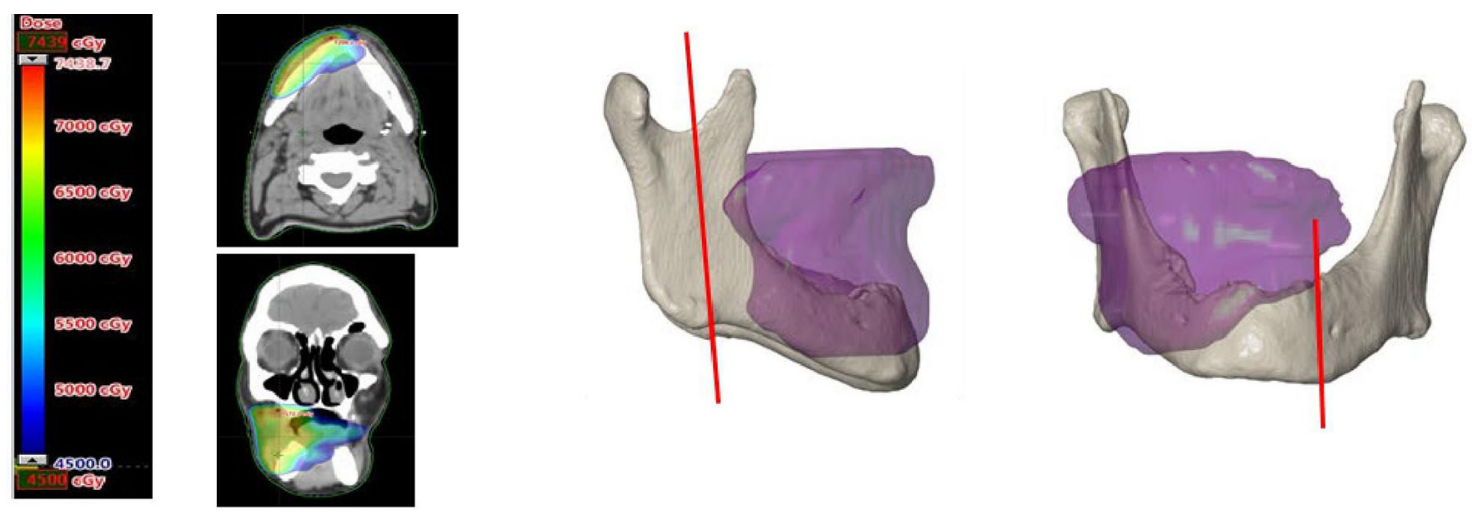

FIGURE 1 | On the left an axial and coronal CT image with superimposed the field of view exposed to 50 Gy or more. On the right a $3 D$ image of the superimposed 50 Gy field on the 3D model of the mandible. The vertical red lines on the mandible mark the planned resection margins. 


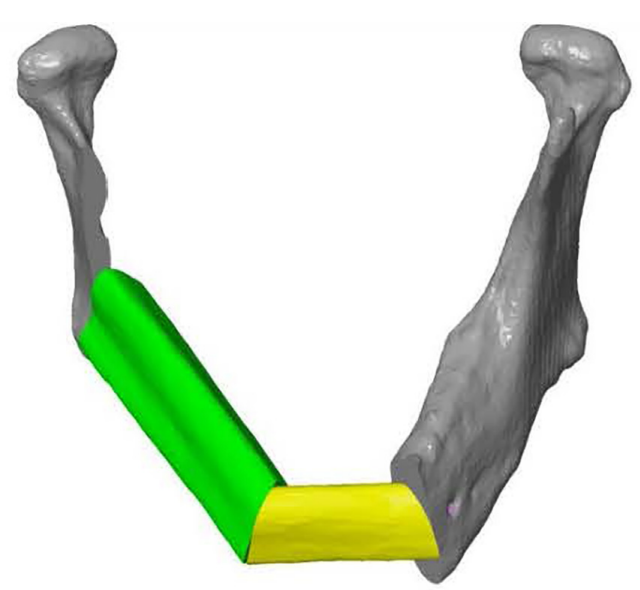

FIGURE 3 | Frontal view of a 3D model of the virtual planned reconstruction in Proplan CMF.

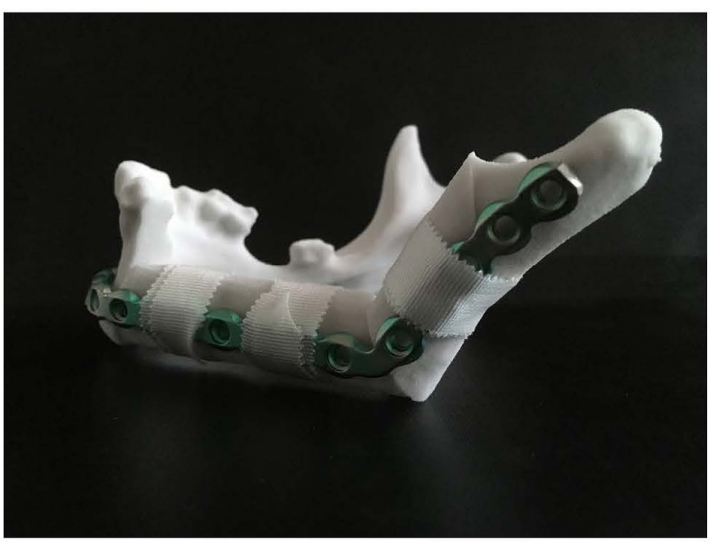

FIGURE 4 | KLS Martin 2.7 mm reconstruction plate bent on a 3D model of the reconstructed mandible, creating a patient specific reconstruction plate. guides were $3 \mathrm{D}$ printed in PA12 material in compliance to ISO 13485 and sterilized.

\section{Surgical Procedure}

Once surgical access and mandibular exposure was obtained, the cutting guide was positioned and fixed to the mandible with four titanium screws $(4 \times \mathrm{KLS}$ Martin 1.5. $\times 7 \mathrm{~mm}$ screws). The resection started with a horizontal osteotomy $2 \mathrm{~mm}$ above the mandibular canal (Figure 6A) and completed with two vertical osteotomies on both sides. The superior part of the mandible was subsequently removed (Figure 6B). After removing the upper part of the IAN cutting guide with a reciprocal saw (Figure 6C), the superior and buccal cortex of the mandibular canal are exposed (Figure 6D) and can be removed with a hard steel burr (Figure 6E). The IAN can be exposed along its entire path with this technique. Once secured, mandibular resection is proceeded as planned (Figure $\mathbf{6 F}$ ). The full surgical process is shown in Figure 6.

\section{Outcome Evaluation}

Accuracy of the mandibular reconstruction was evaluated according to the evaluation method for computer-assisted surgery in mandibular reconstruction described by Van Baar et al $(45,46)$..

A review of Poort et al. (2009) recommends the use of Semmes Weinstein monofilaments as a reliable and reproducible test for measuring sensation in the mental nerve area, in combination with a patient's subjective function by using the visual analogue scale (VAS). We used five Semmes-Weinstein monofilaments (Baseline $^{\circledR}$ tactile $^{\mathrm{TM}}$ monofilament evaluator case) to objectify sensory function of the IAN (in order 300, 40.0, 2.0, 0.4, and 0.07 gram) (48). The monofilaments were placed perpendicular to the front of the chin and lower lip and pressed until the filament begins to deform. At this point, a known reproducible pressure is applied. The monofilaments are placed on a grid of 24 locations on the front of the chin and lower lip (i.e. innervation of one IAN was divided into a 12-point grid). Each approach at each individual measuring point of the grid contains two moments of attention in
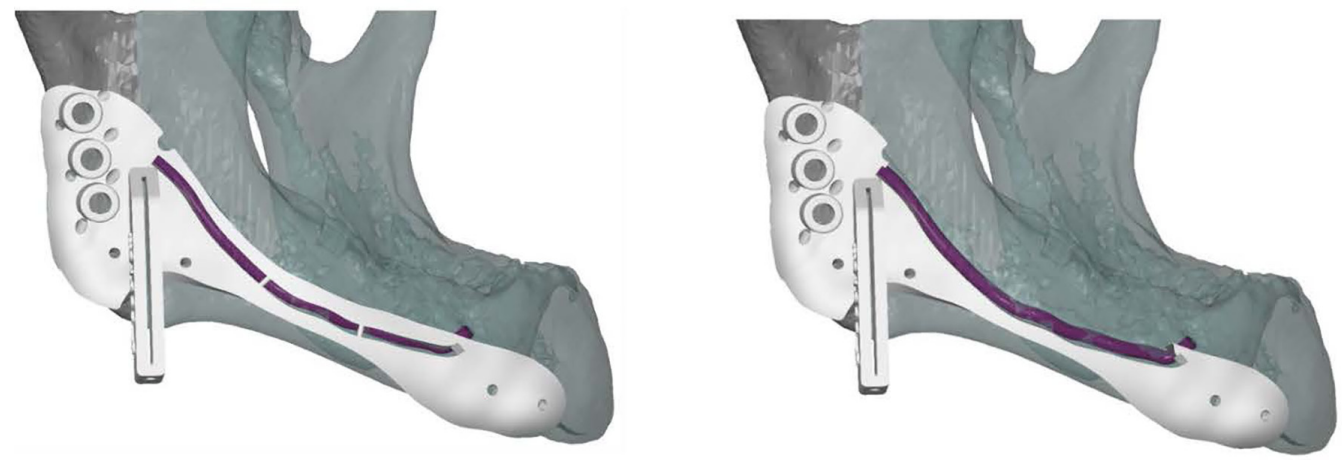

FIGURE 5 | Lateral view of a cutting guide, allowing two-step exteriorization of the inferior alveolar nerve. The purple line indicates the inferior alveolar nerve. The guide shows three drilling holes on the left for plate fixation surrounded by small holes for water cooling during drilling. The guide also includes a saw box to create the osteotomy plane. The two small holes surrounding the saw box and the two small holes on the right side of the guide are used for fixation. 


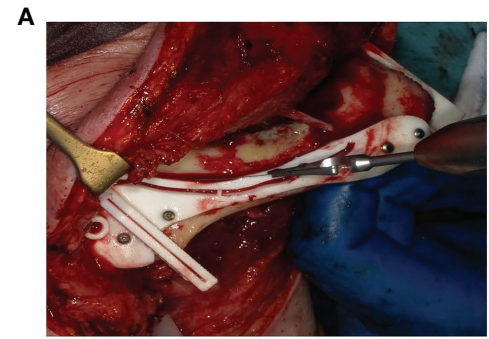

C

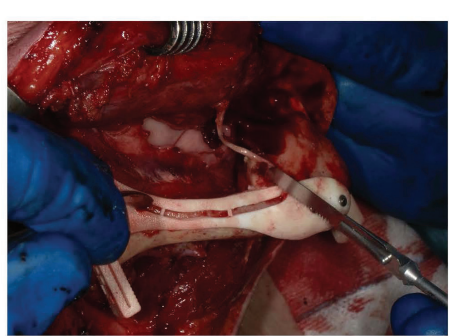

E

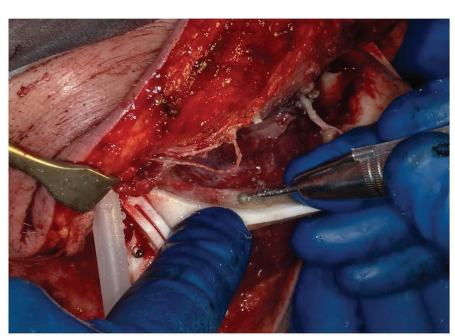

G

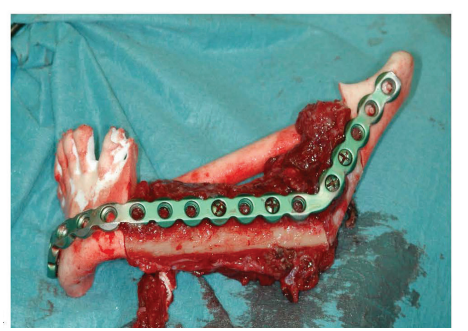

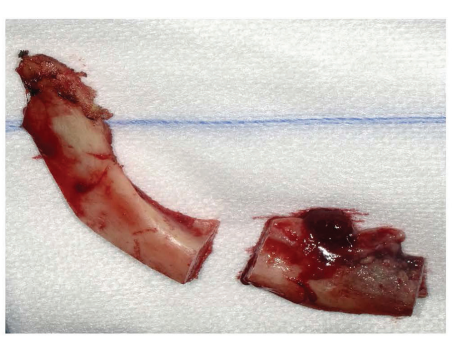

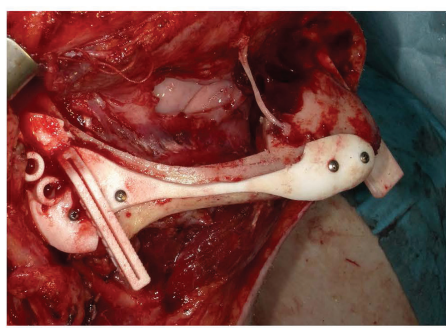

$\mathbf{F}$

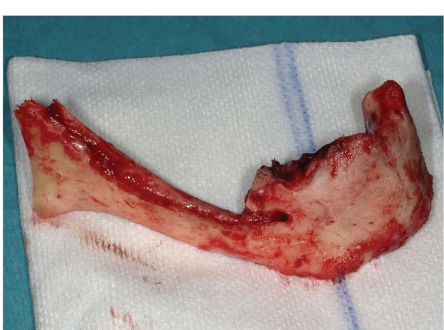

$\mathbf{H}$

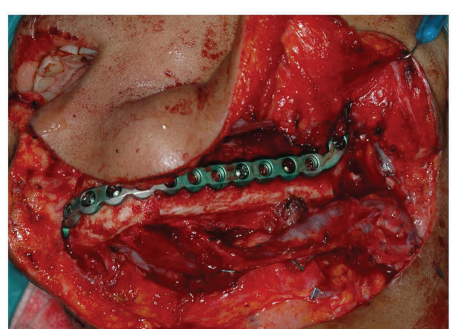

FIGURE 6 | (A) Deroofing of the upper part of the mandible. (B) Removed upper part of the mandible after two vertical osteotomies on both sides. (C) Removal of the upper part of the guide. (D) Accessible buccal bone and $2 \mathrm{~mm}$ roof of the IAN. (E) Buccal corticotomy to expose the IAN. (F) Resected part of the mandible without the right IAN. (G) Fitting of the fibula segments fixated to the patient specific reconstruction plate into a 3D printed mandible including the planned resection. (H) Reconstruction in situ.

which either a test stimulus or a fake stimulus is applied. The fake stimulus is performed by approaching the lower lip/chin with an averted monofilament. The order of test/fake stimulus in the two moments of attention is randomized. A stimulus (test or fake) is preceded by the words spoken: "test 1" and "test 2." After each offer, the patient indicates whether the test stimulus was administered during attention moment 1 or 2 . If the patient does not know exactly, they have to guess ("two alternative forced choice" test procedure). The sensitivity test score is positive if the test stimulus is correctly detected in seven consecutive offers. With seven offers, the chance that a correct result will be achieved by means of guessing is less than $0.01(<0.5)$. At the first error in the series of seven, the test can be terminated immediately with a negative result (49). The total amount of positive reactions were added up for all five monofilaments on each of the 12 locations (i.e. no function of the IAN resulted in a 12 $\times 0$ score of 0 and full function resulted in a $12 \times 5$ score of 60 ). Eventually, the score was converted into a score between 0 and 5 for statistical analysis.

For subjective IAN sensory function two Visual Analog Scales (VAS) were used (Supplementary Figure 1), asking the following questions: "How would you describe the sensation of your lower lip and chin. Place a vertical mark on the line below to indicate the sensation on your lower lip and chin today" and "Place a vertical mark on the line below to indicate the level of sensation on your lower lip and chin you find acceptable in daily life." Both vertical marks were transformed to a score on a scale from 1 "no feeling" to 10 "normal feeling." 
Subjective and objective function of the IAN were determined one day preoperatively (T0) and 2-4 weeks (T1), 2-3 months (T2), 6-7 months (T3), and 1 year or more (T4) postoperatively.

\section{Statistical Analysis}

SPSS Software package (version 26.0 Inc., Chicago, IL, USA) was used for statistical analysis. A paired samples T-test was executed for both subjective and objective IAN function between T0 measurements and T1-T4 measurements. Statistical significance was reached with a twotailed $\mathrm{p}$ value of $<0.05$. As T0 measurements were expected to be different for cases with a pathologic fracture and those without, these cases were analyzed separately.

\section{RESULTS}

\section{Patients}

Between November 2017 and March 2019 five patients were included with a mean age of 53.4 years $(49,50,51,52,53,54,55,56,57)$. A total of seven IAN were preserved (two patients required bilateral IAN preservation). All patient characteristics are shown in Table 2. No patients developed peri-operative complications, in particular there were no clinical or radiological signs of recurrent ORN or non-union for at least 1 year after surgery.

\section{Accuracy}

Table 3 shows all angle deviations (AD) in degrees per angle. The mandibular defect classification of Brown et al. was used (50). Figure 7 shows the panoramic radiographs preoperatively, postoperatively, and after implant placement, with the 3D plan and accuracy measurements added in between.

\section{Nerve Evaluation}

The objective IAN function results are shown in Figures 8A, B. As can be seen in Figure 8B, there were two patients with a pathologic fracture (IAN 1 and IAN 4). Patients without a pathologic fracture
TABLE 3 | Angle deviations in degrees $\left(^{\circ}\right)$ between the preoperative virtual plan and the postoperative result.

\begin{tabular}{|c|c|c|c|c|c|c|c|}
\hline \multirow[t]{2}{*}{ Nr. } & \multirow[t]{2}{*}{ Brown class } & \multicolumn{2}{|c|}{ Axial } & \multicolumn{2}{|c|}{ Coronal } & \multicolumn{2}{|c|}{ Sagittal } \\
\hline & & $\mathbf{L}$ & $\mathbf{R}$ & $\mathbf{L}$ & $\mathbf{R}$ & $\mathbf{L}$ & $\mathbf{R}$ \\
\hline 1 & 1 & 2.40 & 6.42 & 0.54 & 0.06 & 0.28 & 0.10 \\
\hline 2 & III & 0.17 & 2.27 & 0.77 & 2.99 & 1.93 & 1.10 \\
\hline 3 & 1 & 0.94 & 0.12 & 0.73 & 0.49 & 2.17 & 0.11 \\
\hline 4 & $\|$ & 2.45 & 2.84 & 1.03 & 0.32 & 3.78 & 1.49 \\
\hline 5 & III & 0.23 & 1.30 & 0.10 & 2.39 & 7.47 & 2.78 \\
\hline
\end{tabular}

had an average preoperative score of 4.8 . At T1 these patients had an average score of 1.9, which was significantly lower than T0 ( $\mathrm{p}=$ 0.00) (Table 4). However, the objective IAN function improved at T2 up to an average score of 4.3 at T4 for patients without a pathologic fracture $(\mathrm{p}=0.07)$ (Table 5).

As shown in Figure 8C, D, the subjective IAN function (VASscores) showed similar results as the objective IAN function (Figures 8C, D). The light touch test results for the three control IANs were consistent throughout every evaluation moment.

\section{DISCUSSION}

ORN of the jaw is still a common side effect of RT, even after the introduction of intensity-modulated radiotherapy (1-3). ORN can be treated with conservative measures, but in more severe cases (Notani stage III) a segmental resection followed by a vascularized reconstruction flap should be considered $(13,18$, 19). Due to new CAS techniques, preservation of the IAN during mandibular resection is more feasible than ever. Previous studies have evaluated these new CAS techniques for preservation of the IAN during mandibular resection (37-40). These studies have published promising results for postoperative sensory disturbance, but none of them used reliable and reproducible clinical neurosensory tests which are advised for sensory

TABLE 2 | An overview of the included patients and their characteristics.

\begin{tabular}{|c|c|c|c|c|c|c|c|}
\hline Nr. & Age & Sex & Primary diagnosis & TNM & Treatment & Secondary diagnosis & $\begin{array}{l}\text { Included } \\
\text { IAN }\end{array}$ \\
\hline 1 & 49 & $\mathrm{~F}$ & Tonsil R SCC & T2N1 & $\begin{array}{l}\text { Chemoradiotherapy: } \\
70 \text { Gy }\end{array}$ & $\begin{array}{l}\text { ORN + pathologic } \\
\text { fracture }\end{array}$ & $\mathrm{R}$ \\
\hline 2 & 57 & M & $\begin{array}{l}\text { Floor of mouth } \mathrm{R}+\mathrm{L} \\
\text { SCC }\end{array}$ & T3N1 & $\begin{array}{l}\text { Surgery, } \\
\text { Radiotherapy: } \\
70 \text { Gy }\end{array}$ & ORN & $L+R$ \\
\hline 3 & 54 & $\mathrm{~F}$ & Tonsil L SCC & $\mathrm{T} 1 \mathrm{~N} 2 \mathrm{a}$ & $\begin{array}{l}\text { Radiotherapy: } \\
70 \text { Gy }\end{array}$ & $\begin{array}{l}\text { ORN + pathologic } \\
\text { fracture }\end{array}$ & $L$ \\
\hline \multirow[t]{2}{*}{4} & 56 & $M$ & Buccal mucosa R SCC & T1NO & $\begin{array}{l}\text { Surgery } \\
\text { Radiotherapy: } \\
66 \text { Gy }\end{array}$ & ORN & $\mathrm{R}$ \\
\hline & & & $\begin{array}{l}\text { Buccal mucosa L } \\
\text { SCC }\end{array}$ & $\mathrm{T} 2 \mathrm{NO}$ & Surgery & & \\
\hline 5 & 51 & $\mathrm{~F}$ & Floor of mouth L SCC & $\mathrm{T} 2 \mathrm{~N} 2$ & $\begin{array}{l}\text { Surgery, } \\
\text { Chemoradiotherapy: } \\
55 \text { Gy }\end{array}$ & ORN & $L+R$ \\
\hline
\end{tabular}

F, female; M, male; R, right; L, left; SCC, squamous cell carcinoma; ORN, Osteoradionecrosis. 


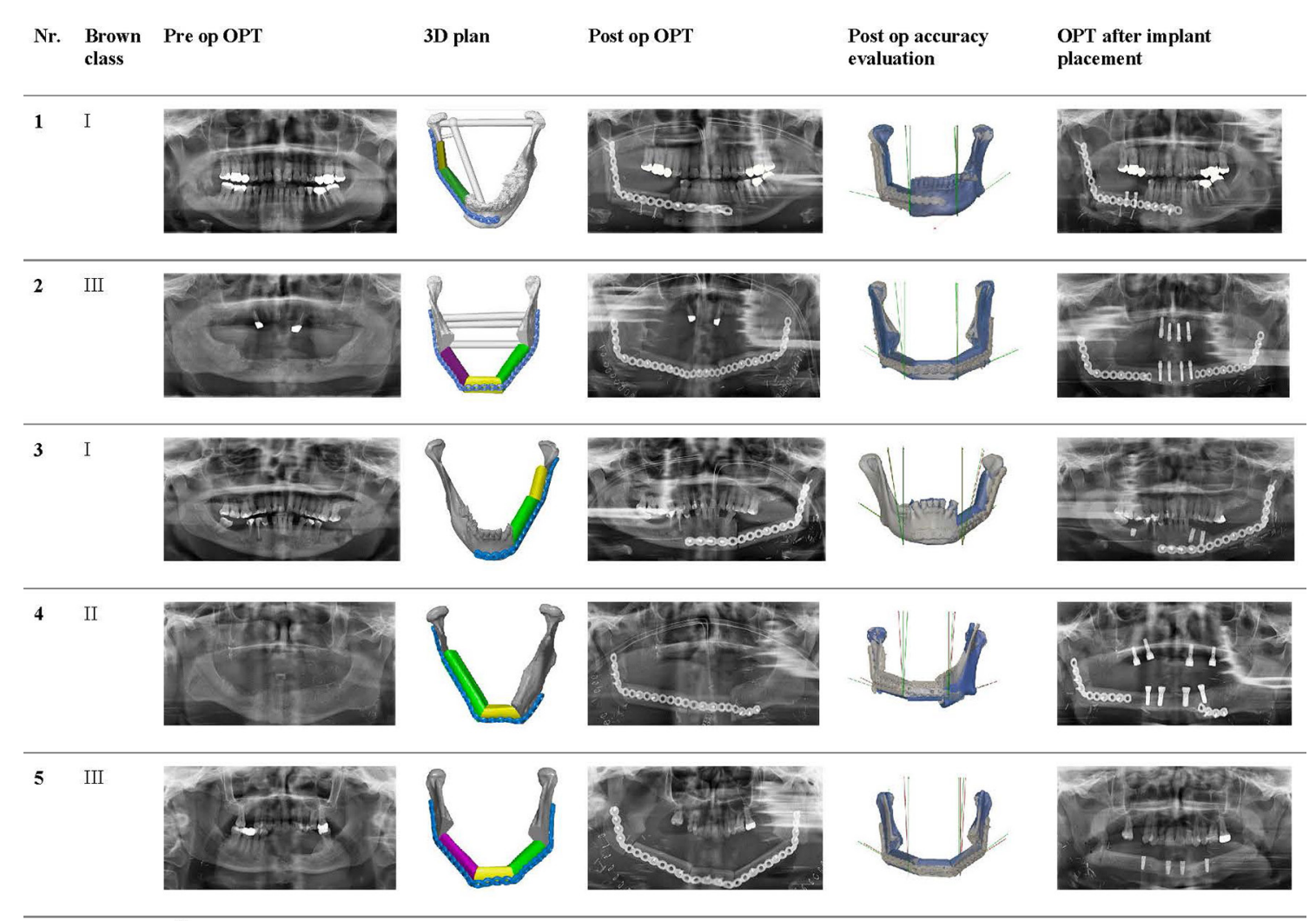

FIGURE 7 | Panoramic radiographs of all included cases preoperatively, postoperatively, and after implant placement, with the 3D plan and accuracy measurements added in between.

evaluation of trigeminal nerve branches $(48,51)$. In addition, the study groups consisted of patients with different preoperative diagnoses.

This study included only patients diagnosed with ORN. The sensory disturbance of the IAN was evaluated using the light touch test with Semmes-Weinstein monofilaments. We also used a VAS-score questionnaire to measure subjective feeling. Poort et al. recommended to use a follow-up regimen of 1 week, 1 month, 3 months, and 1 year (48). However, in this study we did not follow this exact regimen for patient load reasons.

Our results show that IAN preservation using CAS is possible. None of the patients experienced reoccurring ORN within at least 1 year, which suggests enough infected bone was resected. This study suggests that the use of RT isodose curves set to 50Gy can therefore be safely implemented in determining osteotomy planes. Our results show that there was some sensory disturbance of the IAN after surgery, but the mental nerve area regains its sensitivity each following evaluation moment to almost its preoperative sensitivity after 1 year. The cases with a pathological fracture, which already had an IAN sensitivity disturbance, regained even more sensitivity than before the surgery.

The statistical analysis of the average IAN sensitivity (light touch test and VAS) of the "pathological fracture" cases $(n=2)$ did not show a significant difference, this may be a result of the low case number. The "no pathological fracture" cases did show statistical significant results during analysis. We did not take the double inclusion of patients (two "bilateral patients") into account, which may be a weakness of the executed analysis. The three unaffected IANs, used as controls, did not show different sensitivity levels for each evaluation moment, meaning the light touch test with Semmes-Weinstein monofilaments was consistent.

The sensitivity survival and recovery indicates that the nerve tracking technique was sufficient: mandibular canal tracing in steps of $2 \mathrm{~mm}$ in coronal view on the CT of the skull. For the design of the IAN preservation guide we considered the discrepancy of the virtual traced IAN location and the actual location by designing a two-step deroofing process. Once the upper part of the guide was removed, the IAN was still covered with bone and could be carefully exteriorized. By approaching the IAN from the buccal side (buccal corticotomy), it could be lifted easily from the mandibular canal.

In our treatment concept, a virtual model was 3D printed and figured as a template to pre-bent a reconstruction plate into a patient specific reconstruction plate (PSRP) (Figure 4). Subsequently a CT scan of the pre-bent PSRP was made, converted to STL format, and used further along in the virtual 


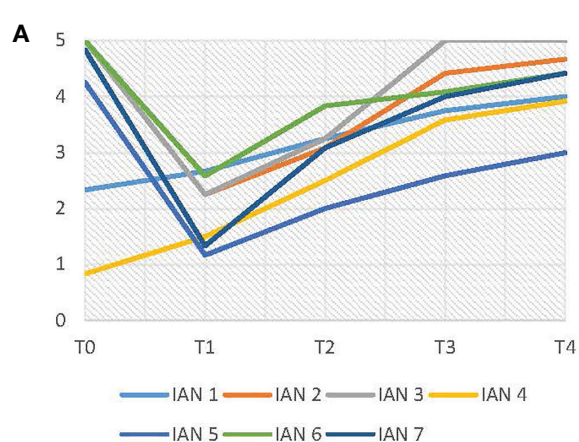

C

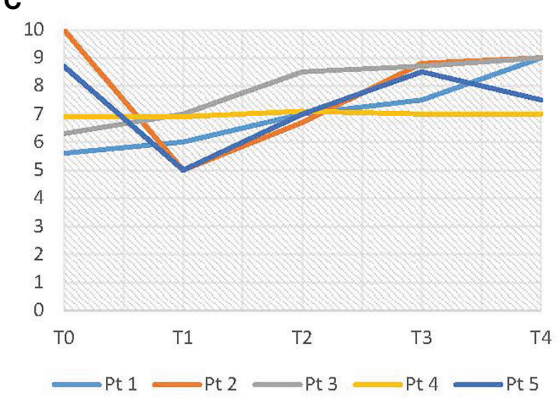

B

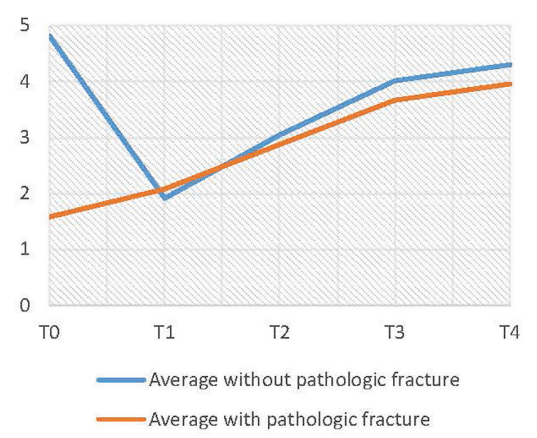

D

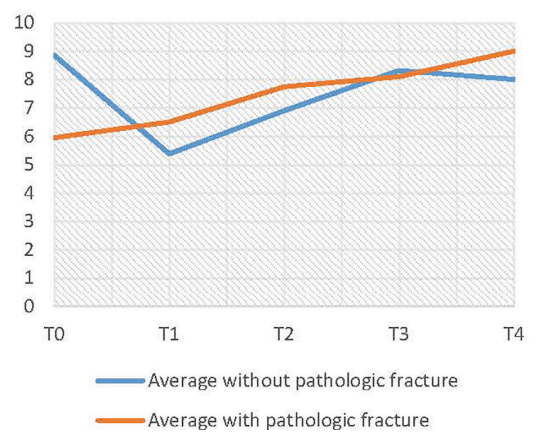

FIGURE 8 | (A) Results of the light touch test. (B) Average results of the light touch test, differentiated on pathologic fracture. (C) VAS-score results. (D) Average VAS-score results, differentiated on pathologic fracture.

TABLE 4 | Paired samples T-test between T0 and T1 for objective IAN function in patients without a pathologic fracture $(n=5) . \alpha=0,05$.

\begin{tabular}{lcccr}
\hline & Mean (SD) & Mean difference (SD) & t-value & p-value \\
\hline T0 & $4,8167(0,32489)$ & $2,9(0,40995)$ & 15,818 & 0,000 \\
T1 & $1,9167(0,62639)$ & & & \\
\hline
\end{tabular}

TABLE 5 | Paired samples t-test TO-T4. Light touch test. Without pathologic fracture $(n=5) . \alpha=0,05$.

\begin{tabular}{lcccr}
\hline & Mean (SD) & Mean difference (SD) & t-value & p-value \\
\hline T0 & $4,8167(0,32489)$ & $0,51667(0,46173)$ & 2,502 & 0,067 \\
T4 & $4,3(0,76513)$ & & & \\
\hline
\end{tabular}

planning. This has the same advantages as a $3 \mathrm{D}$ printed titanium patient specific reconstruction plate, but saves on the high costs of the selective laser sintering manufacturing technique (52). Another advantage of this treatment concept is that no third party is involved in the planning phase, which speeds up the workflow for hospitals with its own 3D lab. Our systematic review of accuracy in mandibular reconstruction using CAS showed that 14 out of the 42 included studies used a standard reconstruction plate which was pre-bent on a $3 \mathrm{D}$ printed model of the virtually planned reconstruction and 12 studies used a 3D printed PSRP. Even though the studies were difficult to compare, there were no striking differences in accuracy or postoperative complications between the studies using a pre-bent reconstruction plate or a $3 \mathrm{D}$ printed PSRP (53).

The measured accuracy of the reconstructions did not show any extreme deviations. Since the accuracy is on such a high level, we believe it is possible to perform computer guided mandibular reconstructions with direct dental implant placement in ORN cases. Especially since in ORN cases the neomandible is constructed with well vascularized donor bone and postoperative RT is not indicated. All patients received dental implants after an average time of 11.6 months (min. 8/ max. 19 months). The use of immediately placed dental implants will improve dental rehabilitation time significantly. Any data on acceptable outcome ranges regarding immediately placed dental implants during mandibular reconstruction has yet to be published.

A shortcoming of this study was the low case number, caused by small numbers of ORN cases. Future multi-center prospective studies need to be carried out in order to validate the results of our novel treatment concept.

\section{CONCLUSION}

Our novel ORN treatment concept shows promising results for implementation of $3 \mathrm{D}$ radiotherapy isodose curve visualization 
and IAN preservation. Sensory function of all IAN recovered after segmental mandibular resection.

\section{DATA AVAILABILITY STATEMENT}

The original contributions presented in the study are included in the article/Supplementary Material. Further inquiries can be directed to the corresponding author.

\section{ETHICS STATEMENT}

The studies involving human participants were reviewed and approved by the Medical Ethics Review Committee of VU University Medical Center (FWA 00017598). The ethics committee waived the requirement of written informed consent for participation.

\section{REFERENCES}

1. Lohia S, Rajapurkar M, Nguyen SA, Sharma AK, Gillespie MB, Day TA. A comparison of outcomes using intensity-modulated radiation therapy and 3dimensional conformal radiation therapy in treatment of oropharyngeal cancer. JAMA Otolaryngol Head Neck Surg (2014) 140:331. doi: 10.1001/ jamaoto.2013.6777

2. Setton J, Caria N, Romanyshyn J, Koutcher L, Wolden SL, Zelefsky MJ, et al. Intensity-modulated radiotherapy in the treatment of oropharyngeal cancer: an update of the Memorial Sloan-Kettering Cancer Center experience. Int $J$ Radiat Oncol Biol Phys (2012) 82:291. doi: 10.1016/j.ijrobp.2010.10.041

3. Vergeer MR, Doornaert PA, Rietveld DH, Leemans CR, Slotman BJ, Langendijk JA. Intensity-modulated radiotherapy reduces radiation-induced morbidity and improves health-related quality of life: results of a nonrandomized prospective study using a standardized follow-up program. Int J Radiat Oncol Biol Phys (2009) 74:1. doi: 10.1016/j.ijrobp.2008.07.059

4. Reuther T, Schuster T, Mende U, Kubler A. Osteoradionecrosis of the jaws as a side effect of radiotherapy of head and neck tumour patients-a report of a thirty year retrospective review. Int J Oral Maxillofac Surg (2003) 32:289. doi: 10.1054/ijom.2002.0332

5. Harris M. The conservative management of osteoradionecrosis of the mandible with ultrasound therapy. Br J Oral Maxillofac Surg (1992) 30:313. doi: 10.1016/0266-4356(92)90181-H

6. Lambade PN, Lambade D, Goel M. Osteoradionecrosis of the mandible: a review. Oral Maxillofac Surg (2013) 17:243. doi: 10.1007/s10006-012-0363-4

7. Marx RE. Osteoradionecrosis: a new concept of its pathophysiology. J Oral Maxillofac Surg (1983) 41:283. doi: 10.1016/0278-2391(83)90294-X

8. Lyons A, Ghazali N. Osteoradionecrosis of the jaws: current understanding of its pathophysiology and treatment. Br J Oral Maxillofac Surg (2008) 46:653. doi: 10.1016/j.bjoms.2008.04.006

9. Schwartz HC, Kagan AR. Osteoradionecrosis of the mandible: scientific basis for clinical staging. Am J Clin Oncol (2002) 25:168. doi: 10.1097/00000421200204000-00013

10. Store G, Boysen M. Mandibular osteoradionecrosis: clinical behaviour and diagnostic aspects. Clin Otolaryngol Allied Sci (2000) 25:378. doi: 10.1046/ j.1365-2273.2000.00367.x

11. De Felice F, Musio D, Tombolini V. Osteoradionecrosis and intensity modulated radiation therapy: An overview. Crit Rev Oncol Hematol (2016) 107:39. doi: 10.1016/j.critrevonc.2016.08.017

12. Mendenhall WM, Suarez C, Genden EM, de Bree R, Strojan P, Langendijk JA, et al. Parameters Associated With Mandibular Osteoradionecrosis. Am J Clin Oncol (2018) 41:1276. doi: 10.1097/COC.0000000000000424

13. Rice N, Polyzois I, Ekanayake K, Omer O, Stassen LF. The management of osteoradionecrosis of the jaws-a review. Surgeon (2015) 13:101. doi: 10.1016/ j.surge.2014.07.003

\section{AUTHOR CONTRIBUTIONS}

Conceived and designed the analysis: GV, JL, LL, TF, and FL. Collected the data: GV, LL, NL, KK, JL, TF, and FL. Contributed data or analysis tools: GV, LL, JL, and KK. Performed the analysis: GV, LL, and JL. Wrote the paper: GV, LL, JL, and FL. All authors contributed to the article and approved the submitted version.

\section{SUPPLEMENTARY MATERIAL}

The Supplementary Material for this article can be found online at: https://www.frontiersin.org/articles/10.3389/fonc.2021. 630123/full\#supplementary-material

Supplementary Figure 1 | Two Visual Analogue Scales (VAS) were asked to the patient to evaluate subjective sensory function of the inferior alveolar nerve.

14. Kluth EV, Jain PR, Stuchell RN, Frich JCJr. A study of factors contributing to the development of osteoradionecrosis of the jaws. J Prosthet Dent (1988) 59:194. doi: 10.1016/0022-3913(88)90015-7

15. Owosho AA, Tsai CJ, Lee RS, Freymiller H, Kadempour A, Varthis S, et al. The prevalence and risk factors associated with osteoradionecrosis of the jaw in oral and oropharyngeal cancer patients treated with intensity-modulated radiation therapy (IMRT): The Memorial Sloan Kettering Cancer Center experience. Oral Oncol (2017) 64:44. doi: 10.1016/j.oraloncology.2016.11.015

16. Nabil S, Samman N. Incidence and prevention of osteoradionecrosis after dental extraction in irradiated patients: a systematic review. Int J Oral Maxillofac Surg (2011) 40:229. doi: 10.1016/j.ijom.2010.10.005

17. Caparrotti F, Huang SH, Lu L, Bratman SV, Ringash J, Bayley A, et al. Osteoradionecrosis of the mandible in patients with oropharyngeal carcinoma treated with intensity-modulated radiotherapy. Cancer (2017) 123:3691. doi: 10.1002/cncr.30803

18. Jacobson AS, Buchbinder D, Hu K, Urken ML. Paradigm shifts in the management of osteoradionecrosis of the mandible. Oral Oncol (2010) 46:795. doi: 10.1016/j.oraloncology.2010.08.007

19. Nadella KR, Kodali RM, Guttikonda LK, Jonnalagadda A. Osteoradionecrosis of the Jaws: Clinico-Therapeutic Management: A Literature Review and Update. J Maxillofac Oral Surg (2015) 14:891. doi: 10.1007/s12663-0150762-9

20. Wong JK, Wood RE, McLean M. Conservative management of osteoradionecrosis. Oral Surg Oral Med Oral Pathol Oral Radiol Endod (1997) 84:16. doi: 10.1016/S1079-2104(97)90287-0

21. Notani K, Yamazaki Y, Kitada H, Sakakibara N, Fukuda H, Omori K, et al. Management of mandibular osteoradionecrosis corresponding to the severity of osteoradionecrosis and the method of radiotherapy. Head Neck (2003) 25:181. doi: 10.1002/hed.10171

22. Shaw R, Tesfaye B, Bickerstaff M, Silcocks P, Butterworth C. Refining the definition of mandibular osteoradionecrosis in clinical trials: The cancer research UK HOPON trial (Hyperbaric Oxygen for the Prevention of Osteoradionecrosis). Oral Oncol (2017) 64:73. doi: 10.1016/ j.oraloncology.2016.12.002

23. Store G, Larheim TA. Mandibular osteoradionecrosis: a comparison of computed tomography with panoramic radiography. Dentomaxillofac Radiol (1999) 28:295. doi: 10.1038/sj.dmfr.4600461

24. Rodby KA, Turin S, Jacobs RJ, Cruz JF, Hassid VJ, Kolokythas A, et al. Advances in oncologic head and neck reconstruction: systematic review and future considerations of virtual surgical planning and computer aided design/ computer aided modeling. J Plast Reconstr Aesthet Surg (2014) 67:1171. doi: 10.1016/j.bjps.2014.04.038

25. Hirsch DL, Garfein ES, Christensen AM, Weimer KA, Saddeh PB, Levine JP. Use of computer-aided design and computer-aided manufacturing to produce orthognathically ideal surgical outcomes: a paradigm shift in head and neck 
reconstruction. J Oral Maxillofac Surg (2009) 67:2115. doi: 10.1016/ j.joms.2009.02.007

26. Nilsson J, Hindocha N, Thor A. Time matters - Differences between computer-assisted surgery and conventional planning in craniomaxillofacial surgery: A systematic review and meta-analysis. $J$ Craniomaxillofac Surg (2020) 48:132. doi: 10.1016/j.jcms.2019.11.024

27. Roser SM, Ramachandra S, Blair H, Grist W, Carlson GW, Christensen AM, et al. The accuracy of virtual surgical planning in free fibula mandibular reconstruction: comparison of planned and final results. J Oral Maxillofac Surg (2010) 68:2824. doi: 10.1016/j.joms.2010.06.177

28. Antony AK, Chen WF, Kolokythas A, Weimer KA, Cohen MN. Use of virtual surgery and stereolithography-guided osteotomy for mandibular reconstruction with the free fibula. Plast Reconstr Surg (2011) 128:1080. doi: 10.1097/PRS.0b013e31822b6723

29. Hanasono MM, Skoracki RJ. Computer-assisted design and rapid prototype modeling in microvascular mandible reconstruction. Laryngoscope (2013) 123:597. doi: 10.1002/lary.23717

30. Avraham T, Franco P, Brecht LE, Ceradini DJ, Saadeh PB, Hirsch DL, et al. Functional outcomes of virtually planned free fibula flap reconstruction of the mandible. Plast Reconstr Surg (2014) 134:628e. doi: 10.1097/ PRS.0000000000000513

31. Kraeima J, Steenbakkers R, Spijkervet FKL, Roodenburg JLN, Witjes MJH. Secondary surgical management of osteoradionecrosis using threedimensional isodose curve visualization: a report of three cases. Int J Oral Maxillofac Surg (2018) 47:214. doi: 10.1016/j.ijom.2017.08.002

32. Smith JG, Elias LA, Yilmaz Z, Barker S, Shah K, Shah S, et al. The psychosocial and affective burden of posttraumatic neuropathy following injuries to the trigeminal nerve. J Orofac Pain (2013) 27:293. doi: 10.11607/jop.1056

33. Marchena JM, Padwa BL, Kaban LB. Sensory abnormalities associated with mandibular fractures: incidence and natural history. J Oral Maxillofac Surg (1998) 56:822. doi: 10.1016/S0278-2391(98)90003-9

34. Kuriakose MA, Lee JJ, DeLacure MD. Inferior alveolar nerve-preserving mandibulectomy for nonmalignant lesions. Laryngoscope (2003) 113:1269. doi: 10.1097/00005537-200307000-00029

35. Wu TC, Chen Z, Tian FC, Tian QZ, You CT. Ameloblastoma of the mandible treated by resection, preservation of the inferior alveolar nerve, and bone grafting. J Oral Maxillofac Surg (1984) 42:93. doi: 10.1016/0278-2391(84) 90318-5

36. Nocini PF, De Santis D, Fracasso E, Zanette G. Clinical and electrophysiological assessment of inferior alveolar nerve function after lateral nerve transposition. Clin Oral Implants Res (1999) 10:120. doi: 10.1034/j.1600-0501.1999.100206.x

37. Chen MJ, Yang C, Huang D, He DM, Wang YW, Zhang WH. Modified technique for preservation of inferior alveolar nerve during mandibulectomy. Head Neck (2017) 39:2562. doi: 10.1002/hed.24924

38. Zhou Z, Zhao H, Zhang S, Zheng J, Yang C. Evaluation of accuracy and sensory outcomes of mandibular reconstruction using computer-assisted surgical simulation. J Craniomaxillofac Surg (2019) 47:6. doi: 10.1016/ j.jcms.2018.10.002

39. Ricotta F, Battaglia S, Sandi A, Pizzigallo A, Marchetti C, Tarsitano A. Use of a CAD-CAM inferior alveolar nerve salvage template during mandibular resection for benign lesionsUtilizzo di una guida CAD-CAM per la preservazione del nervo alveolare inferiore durante le resezioni mandibolari nelle lesioni benigne. Acta Otorhinolaryngol Italica (2019) 39:117. doi: 10.14639/0392-100X-2408

40. Huang D, Chen M, He D, Yang C, Yuan J, Bai G, et al. Preservation of the inferior alveolar neurovascular bundle in the osteotomy of benign lesions of the mandible using a digital template. Br J Oral Maxillofacial Surg (2015) 53:637. doi: 10.1016/j.bjoms.2015.04.013

41. Ang E, Black C, Irish J, Brown DH, Gullane P, O'Sullivan B, et al. Reconstructive options in the treatment of osteoradionecrosis of the craniomaxillofacial skeleton. Br J Plast Surg (2003) 56:92. doi: 10.1016/ S0007-1226(03)00085-7

42. Bak M, Jacobson AS, Buchbinder D, Urken ML. Contemporary reconstruction of the mandible. Oral Oncol (2010) 46:71. doi: 10.1016/ j.oraloncology.2009.11.006

43. Pohlenz P, Blessmann M, Blake F, Li L, Schmelzle R, Heiland M. Outcome and complications of 540 microvascular free flaps: the Hamburg experience. Clin Oral Investig (2007) 11:89. doi: 10.1007/s00784-006-0073-0

44. Hayden RE, Mullin DP, Patel AK. Reconstruction of the segmental mandibular defect: current state of the art. Curr Opin Otolaryngol Head Neck Surg (2012) 20:231. doi: 10.1097/MOO.0b013e328355d0f3

45. van Baar GJC, Liberton N, Forouzanfar T, Winters HAH, Leusink FKJ. Accuracy of computer-assisted surgery in mandibular reconstruction: A postoperative evaluation guideline. Oral Oncol (2019) 88:1. doi: 10.1016/ j.oraloncology.2018.11.013

46. van Baar GJC, Liberton N, Winters HAH, Leeuwrik L, Forouzanfar T, Leusink FKJ. A Postoperative Evaluation Guideline for Computer-Assisted Reconstruction of the Mandible. J Vis Exp (2020) 28(155). doi: 10.3791/60363

47. Gerlach NL, Meijer GJ, Maal TJ, Mulder J, Rangel FA, Borstlap WA, et al. Reproducibility of 3 different tracing methods based on cone beam computed tomography in determining the anatomical position of the mandibular canal. $J$ Oral Maxillofac Surg (2010) 68:811. doi: 10.1016/j.joms.2009.09.059

48. Poort LJ, van Neck JW, van der Wal KG. Sensory testing of inferior alveolar nerve injuries: a review of methods used in prospective studies. J Oral Maxillofac Surg (2009) 67:292. doi: 10.1016/j.joms.2008.06.076

49. Vriens JP, van der Glas HW, Koole R. [Repair and revision 9. Peripheral trigeminal nerve injury]. Ned Tijdschr Tandheelkd (2002) 106(3):95-9.

50. Brown JS, Barry C, Ho M, Shaw R. A new classification for mandibular defects after oncological resection. Lancet Oncol (2016) 17:e23. doi: 10.1016/S14702045(15)00310-1

51. Devine M, Hirani M, Durham J, Nixdorf DR, Renton T. Identifying criteria for diagnosis of post-traumatic pain and altered sensation of the maxillary and mandibular branches of the trigeminal nerve: a systematic review. Oral Surg Oral Med Oral Pathol Oral Radiol (2018) 125:526. doi: 10.1016/ j.oooo.2017.12.020

52. Zweifel DF, Simon C, Hoarau R, Pasche P, Broome M. Are virtual planning and guided surgery for head and neck reconstruction economically viable? $J$ Oral Maxillofac Surg (2015) 73:170. doi: 10.1016/j.joms.2014.07.038

53. van Baar GJC, Forouzanfar T, Liberton N, Winters HAH, Leusink FKJ. Accuracy of computer-assisted surgery in mandibular reconstruction: A systematic review. Oral Oncol (2018) 84:52. doi: 10.1016/j.oraloncology.2018.07.004

Conflict of Interest: The authors declare that the research was conducted in the absence of any commercial or financial relationships that could be construed as a potential conflict of interest.

Copyright $\odot 2021$ van Baar, Leeuwrik, Lodders, Liberton, Karagozoglu, Forouzanfar and Leusink. This is an open-access article distributed under the terms of the Creative Commons Attribution License (CC BY). The use, distribution or reproduction in other forums is permitted, provided the original author(s) and the copyright owner(s) are credited and that the original publication in this journal is cited, in accordance with accepted academic practice. No use, distribution or reproduction is permitted which does not comply with these terms. 